\title{
Comment on "Antibiotic Resistance Profiles of Haemophilus influenzae Isolates from Children in 2016: A Multicenter Study in China"
}

\author{
Meltem Karabay (iD) ${ }^{1}$ and Oguz Karabay (D) $^{2}$ \\ ${ }^{1}$ Sakarya University Faculty of Medicine, Department of Neonatology, Sakarya, Turkey \\ ${ }^{2}$ Sakarya University Faculty of Medicine, Department of Infectious Diseases, Sakarya, Turkey \\ Correspondence should be addressed to Meltem Karabay; karabay@sakarya.edu.tr \\ Received 9 September 2019; Accepted 3 June 2020; Published 17 February 2021 \\ Academic Editor: Louis DeTolla
}

Copyright (c) 2021 Meltem Karabay and Oguz Karabay. This is an open access article distributed under the Creative Commons Attribution License, which permits unrestricted use, distribution, and reproduction in any medium, provided the original work is properly cited.

We read with great interest the article by Wang et al. recently published in BioMed Research International. [1] The authors identified antibiotic susceptibility of Haemophilus influenzae strains obtained from six children's hospitals in different regions of China. However, we have two concerns with the study. Upon careful examination of the distribution of the obtained samples, we understood that 1,558 (75\%) samples were obtained from sputum and 107 (5\%) samples were obtained from throat swabs. Firstly, it is necessary to mention that the presence of $H$. influenzae in the throat specimens or sputum does not indicate that it is a causative agent. $H$. influenzae is one of the most common contaminants, especially in throat and sputum samples. The presence of this bacterium in sputum or some clinical specimens does not indicate that $H$. influenzae is the cause of the disease. Therefore, the results of the antibiograms obtained from these samples cannot be evaluated as if they were patient samples.

Secondly, we found that $H$. influenzae was isolated in 231 vaginal specimens. Some of the most frequent and expected pathogenic causes of vaginitis are Candida spp., Trichomonas vaginalis, and Gardnerella vaginalis. In contrast, Haemophilus spp. are not a commonly expected cause of vaginitis. We are therefore of the opinion that the 231 (11\%) vaginal $H$. influenzae strains are likely to be only contamination. As a result, we think that many of the results of this antibiogram obtained by the authors do not show causative bacteria, but rather flora member bacteria indicating the presence of flora rather than the disease. The results may have been more conclusive if the study had aimed to determine the resistance rate of $H$. influenzae and collected data from sterile tissue samples such as blood and CSF.

\section{Conflicts of Interest}

The authors declare that they have no conflicts of interest.

\section{References}

[1] H.-J. Wang, C.-Q. Wang, C.-Z. Hua et al., "Antibiotic Resistance Profiles of Haemophilus influenzae Isolates from Children in 2016: A Multicenter Study in China," Canadian Journal of Infectious Diseases and Medical Microbiology, vol. 2019, Article ID 6456321, 6 pages, 2019. 